Supporting Information for the manuscript:

\title{
The Discovery and Biosynthesis of Nicotinic Myxochelins from an Archangium
}

\section{sp. SDU34}

De-Gao Wang, ${ }^{\dagger}, \perp$ Luo Niu, ${ }^{\dagger}, \perp$ Zhao-Min Lin, ${ }^{\ddagger}$ Jing-Jing Wang, ${ }^{\dagger}$ Dong-Fang Gao, ${ }^{\ddagger}$ Hai-Yan Sui, ${ }^{\dagger}$ YueZhong Li,t, * Changsheng Wu ${ }^{\dagger, ~ * ~}$

† State Key Laboratory of Microbial Technology, Institute of Microbial Technology, Shandong University, Qingdao, People's Republic of China

¥ Institute of Medical Science, The Second Hospital, Cheeloo College of Medicine, Shandong University, Jinan 250033, People's Republic of China

${ }^{*}$ Corresponding authors:

wuchangsheng@sdu.edu.cn; Tel. (+86) 532-58631538; ORCID ID 0000-0003-1310-0089.

lilab@sdu.edu.cn; Tel. (+86) 532 58631539; Fax. (+86) 532 58631539; ORCID ID, 0000-00018336-6638.

${ }^{\perp}$ D.-G. Wang and L. Niu contributed equally to this work. 


\section{Bioassay methods}

\section{Antibacterial activity test}

Antimicrobial activity was determined using agar diffusion assay. ${ }^{1}$ Single colonies of Staphylococcus aureus, Acinetobacter baumannii and Candida albicans were picked and inoculated into $8 \mathrm{~mL}$ TSB liquid medium, respectively. The overnight culture at $37^{\circ} \mathrm{C}$ were diluted to $1 \times 10^{7} \mathrm{cells} / \mathrm{mL}$ with TSB liquid medium. The respective compound was dissolved in methanol $(4 \mathrm{mg} / \mathrm{mL})$, and $5 \mu$ of the solution was applied on a paper disk. The disks were then placed onto an agar plate containing a soft agar overlay with either Staphylococcus aureus, Acinetobacter baumannii, or Candida albicans. Kanamycin (for S. aureus and A. baumannii) and apramycin (for $C$. albicans) at a concentration of $1 \mathrm{mg} / \mathrm{mL}$ were used as positive controls, and the solvent methanol as the negative control. After incubation at $37^{\circ} \mathrm{C}$ for $18 \mathrm{~h}$, growth inhibition zones (in $\mathrm{mm}$ ) were recorded as antimicrobial activity.

\section{Chrome Azurol S Assay²}

A conical flask containing $21.9 \mathrm{mg}$ of the hexadecyltrimethylammonium bromide (CTAB) and $25 \mathrm{~mL}$ of water was heated to $35^{\circ} \mathrm{C}$. To this solution, a mixture of $1.5 \mathrm{~mL}$ iron (III) solution (in a $10 \mathrm{mM}$ aqueous $\mathrm{HCl}$ solution) and $7.5 \mathrm{~mL}$ of $2 \mathrm{mM}$ aqueous chrome azurol $\mathrm{S}$ (CAS) was added with stirring. In a separate Erlenmeyer flask, $9.76 \mathrm{~g}$ of 2-(N-morpholino) ethanesulfonic acid (MES) was dissolved in $50 \mathrm{~mL}$ of $\mathrm{H}_{2} \mathrm{O}$ at room temperature, and a $50 \% \mathrm{KOH}$ solution was used to achieve $\mathrm{pH}=5.6$. Poured this buffered solution into the Erlenmeyer flask containing the CTAB-CAS-Fe (III) solution and added water up to a final volume of $100 \mathrm{~mL}$. Next, $100 \mu \mathrm{L}$ of the resultant solution was pipetted into each well of 96-well microplate, and then each well was added with $100 \mu \mathrm{L}$ of the tested compounds or deferoxamine mesylate in $\mathrm{H}_{2} \mathrm{O}$, to achieve final concentrations ranging from $1.28 \mathrm{mM}$ to $0 \mathrm{mM}$. Then, the 96 -well microplate was incubated at $37^{\circ} \mathrm{C}$ for 3 hours, and the siderophore function was judged by the visual inspection of color changes.

\section{Cytotoxicity Assay}

The human prostate carcinoma cell line PC3, human lung carcinoma cancer cell line A549 and hepatocarcinoma cell line HepG-2 were cultured in RPMI 1640 medium (Hyclone, Logan, UT) 
supplemented with $10 \%$ fetal bovine serum (Hyclone), $100 \mathrm{U} / \mathrm{mL}$ penicillin and $100 \mu \mathrm{g} / \mathrm{mL}$ streptomycin, respectively. The cells were incubated in $5 \% \quad \mathrm{CO}_{2}$ at $37{ }^{\circ} \mathrm{C}$ until they reached approximately $50-70 \%$ confluence, and then treated with various concentrations of compounds dissolved in DMSO. DMSO was used as the negative control. An MTT [3-(4,5-dimethylthiazol-2-yl)2,5-diphenyl- 2H-tetrazolium bromide, Sigma, St.Louis, MO] assay was used to measure the proliferation of cells treated with different compounds in 96 -well plates ${ }^{3}$. After $24 \mathrm{~h}$ treatment with DMSO, different concentrations of tested compounds, as well as the positive control cisplatin in DMSO, the cells were incubated with $10 \mu \mathrm{L}$ of MTT $(5 \mathrm{mg} / \mathrm{mL})$ for $4 \mathrm{~h}$. Formazan product was then solubilized with $100 \mu \mathrm{L}$ of DMSO, and the absorbance was measured at $570 \mathrm{nM}$ by a plate reader (Bio-Rad, USA). $I_{50}$ values (the concentration resulting in $50 \%$ inhibition of cell growth) for compounds were calculated from the plotted results, with untreated cells being set at $100 \%$. All experiments were conducted at three replicates. 
Table S1. ${ }^{1} \mathrm{H}$ and ${ }^{13} \mathrm{C}$ NMR data of myxochelins $\mathrm{N}(1)$ and $\mathrm{O}(2)$ in $\mathrm{CD}_{3} \mathrm{OD}$

\begin{tabular}{|c|c|c|c|c|}
\hline \multirow[b]{2}{*}{ Pos. } & \multicolumn{2}{|r|}{1} & \multicolumn{2}{|r|}{2} \\
\hline & $\delta_{\mathrm{C}}$, type & $\delta_{\mathrm{H}}$, mult. $(\mathrm{J}$ in $\mathrm{Hz})$ & $\delta_{C}$, type & $\delta_{\mathrm{H}}$, mult. $(\mathrm{J}$ in $\mathrm{Hz})$ \\
\hline 1 & $65.9, \mathrm{CH}_{2}$ & $3.66, \mathrm{dd}(6.0,3.0)$ & $72.4, \mathrm{CH}_{2}$ & $\begin{array}{l}\text { a: } 4.08, \mathrm{dd}(9.0,6.6) \\
\text { b: } 4.52, \mathrm{t}(8.4)\end{array}$ \\
\hline 2 & $54.2, \mathrm{CH}$ & $4.18, \mathrm{~m}$ & $54.7, \mathrm{CH}$ & $3.92, \mathrm{~m}$ \\
\hline 3 & $32.4, \mathrm{CH}_{2}$ & $\begin{array}{l}\text { a: } 1.67, \mathrm{~m} \\
\text { b: } 1.77 . \mathrm{m}\end{array}$ & $36.9, \mathrm{CH}_{2}$ & $1.65, \mathrm{~m}$ \\
\hline 4 & $25.4, \mathrm{CH}_{2}$ & $1.53, \mathrm{~m}$ & 24.3, $\mathrm{CH}_{2}$ & $1.48, m$ \\
\hline 5 & $31.1, \mathrm{CH}_{2}$ & $1.72, \mathrm{~m}$ & $31.1, \mathrm{CH}_{2}$ & $1.70, \mathrm{~m}$ \\
\hline 6 & 41.7, $\mathrm{CH}_{2}$ & $3.44, \operatorname{td}(7.2,3.0)$ & 41.6, $\mathrm{CH}_{2}$ & $3.45, \mathrm{t}(7.2)$ \\
\hline $1^{\prime}$ & $168.5, \mathrm{C}$ & - & 168.6, C & \\
\hline $2^{\prime}$ & 132.8, C & - & 133.0, C & - \\
\hline $3^{\prime}$ & 137.6, CH & $8.21, \mathrm{dt}(8.4,1.8)$ & $137.8, \mathrm{CH}$ & $8.27, \mathrm{dt}(7.8,1.8)$ \\
\hline $4^{\prime}$ & $125.7, \mathrm{CH}$ & $7.53, \mathrm{ddd}(7.8,4.8,1.2)$ & $126.0, \mathrm{CH}$ & 7.57, ddd $(7.8,4.8,0.8)$ \\
\hline $5^{\prime}$ & $153.2, \mathrm{CH}$ & $8.68, \mathrm{dt}(4.8,1.8)$ & $153.5, \mathrm{CH}$ & $8.71, \mathrm{dd}(4.8,1.8)$ \\
\hline $6^{\prime}$ & $149.8, \mathrm{CH}$ & $8.96, d(0.6)$ & $149.9, \mathrm{CH}$ & 8.99 , dd $(2.4,0.6)$ \\
\hline $1 "$ & 168.7, C & - & 163.2, C & (1) \\
\hline 2" & 133.0, C & - & & \\
\hline 3" & 137.8, CH & $8.25, \mathrm{dt}(8.4,1.8)$ & & \\
\hline 4" & $125.8, \mathrm{CH}$ & 7.54, ddd $(7.8,4.8,1.2)$ & & \\
\hline 5" & 153.3, CH & $8.69, \mathrm{dt}(4.8,1.8)$ & & \\
\hline 6" & $149.9, \mathrm{CH}$ & $8.99, d(0.6)$ & & \\
\hline
\end{tabular}<smiles>O=C(NCCCC[C@H](CO)NC(=O)c1cccnc1)c1cccnc1</smiles><smiles>O=C1NC(CCCCNC(=O)c2cccnc2)CO1</smiles> 
Table S2. The $m x c$ gene cluster organization in Archangium sp. SDU34.

\begin{tabular}{|c|c|c|c|c|c|}
\hline ORF & $\begin{array}{l}\text { Gene } \\
\text { size } \\
(b p)\end{array}$ & $\begin{array}{l}\text { Gene } \\
\text { name }\end{array}$ & Proposed function & NCBI similarity & ID\% \\
\hline 1 & 774 & $m x c C$ & 2,3-DHBA biosynthesis & $\begin{array}{l}\text { 2,3-dihydroxybenzoate dehydrogenase [Archangium sp. } \\
\mathrm{Cb} \text { G35] }\end{array}$ & $90 \%$ \\
\hline 2 & 1227 & $m \times c D$ & 2,3-DHBA biosynthesis & Isochorismate synthase [Archangium gephyra] & $86 \%$ \\
\hline 3 & 1653 & $m \times c E$ & 2,3-DHBA-AMP ligase & $\begin{array}{l}\text { (2,3-dihydroxybenzoyl)adenylate synthase [Archangium } \\
\text { gephyra] }\end{array}$ & $84 \%$ \\
\hline 4 & 912 & $m x c F$ & $\begin{array}{l}\text { Isochorismatase/aryl } \\
\text { carrier protein }\end{array}$ & isochorismatase family protein [Archangium sp. Cb G35] & $82 \%$ \\
\hline 5 & 4323 & $m \times c G$ & NRPS & $\begin{array}{l}\text { non-ribosomal peptide synthetase [Archangium } \\
\text { violaceum] }\end{array}$ & $83 \%$ \\
\hline 6 & 1383 & $\operatorname{AroA}_{A 5}$ & 2,3-DHBA biosynthesis & $\begin{array}{l}\text { 3-deoxy-7-phosphoheptulonate synthase class II } \\
\text { [Archangium gephyra]; AroAA5 [Stigmatella aurantiaca } \\
\text { Sg a15] }\end{array}$ & $86 \%$ \\
\hline 7 & 2538 & $m x c H$ & Transporter & $\begin{array}{l}\text { TonB-dependent siderophore myxochelin receptor MxcH } \\
\text { [Vitiosangium sp. GDMCC 1.1324] }\end{array}$ & $69 \%$ \\
\hline 8 & 1239 & $m \times c J$ & Mxcl protein & hypothetical protein [Archangium gephyra] & $68 \%$ \\
\hline 9 & 1101 & $m \times c O$ & Unkown function & PepSY domain-containing protein [Archangium gephyra] & $81 \%$ \\
\hline 10 & 750 & $m \times c Q$ & Transporter & $\begin{array}{l}\text { MotA/TolQ/ExbB proton channel family protein } \\
\text { [Vitiosangium sp. GDMCC 1.1324] }\end{array}$ & $83 \%$ \\
\hline 11 & 429 & $m \times c R$ & Transporter & $\begin{array}{l}\text { biopolymer transporter ExbD [Vitiosangium sp. GDMCC } \\
\text { 1.1324] }\end{array}$ & $75 \%$ \\
\hline 12 & 843 & $m \times c B$ & Transporter & TonB family protein [Pyxidicoccus caerfyrddinensis] & $62 \%$ \\
\hline
\end{tabular}


Figure S1. The phylogenetic tree reconstructed based on 16S rRNA gene sequences using the maximum-likelihood method, showing the position of strain SDU34 among related taxa. Bootstrap values based on 1000 replications are listed as percentages at the branching points. Bar, 0.01 substitutions per nucleotide position.

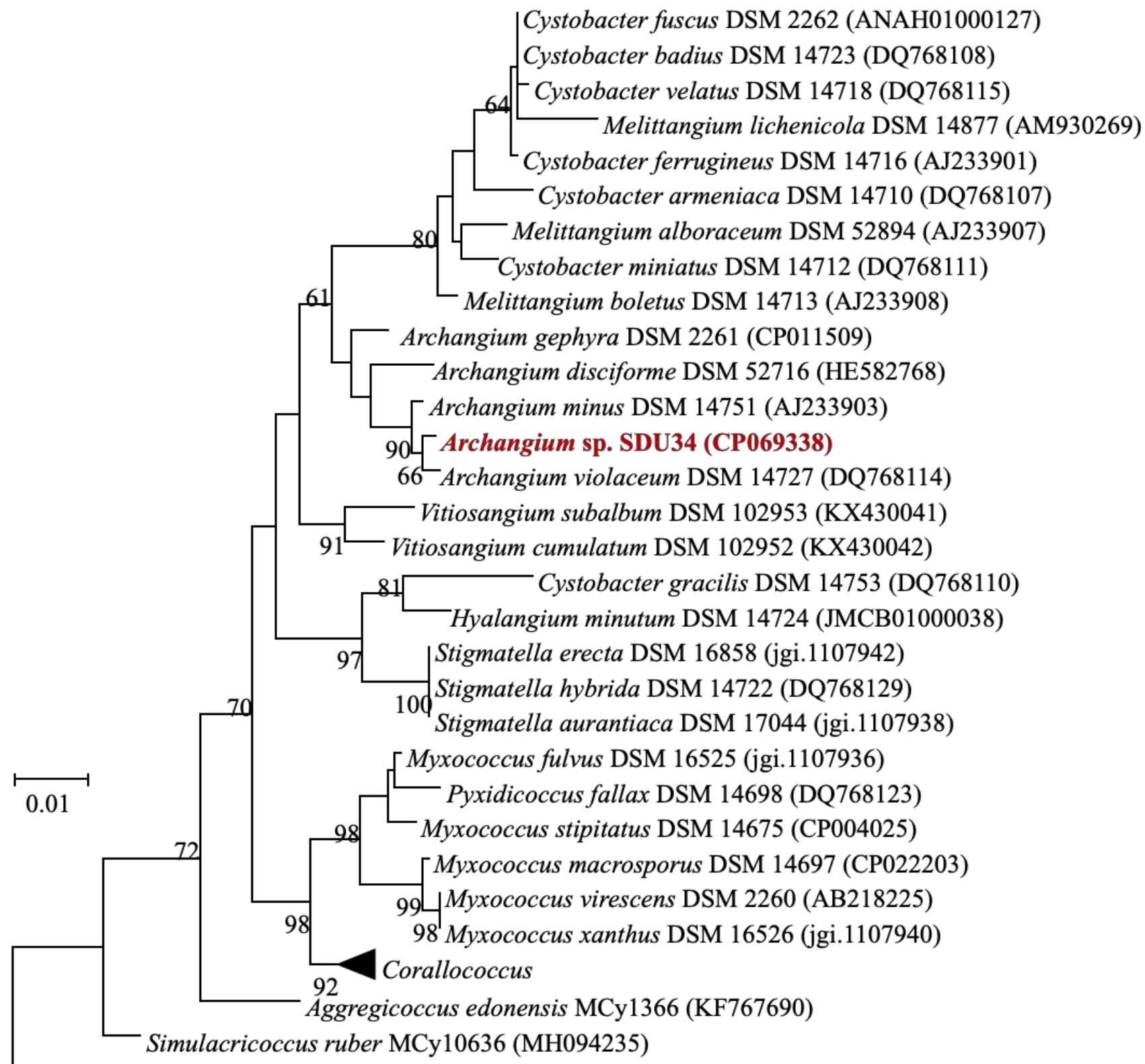


Figure S2. HMBC ( $\sim$ ) and COSY ( $(\boldsymbol{)})$ correlations for myxochelins N (1) and O (2).

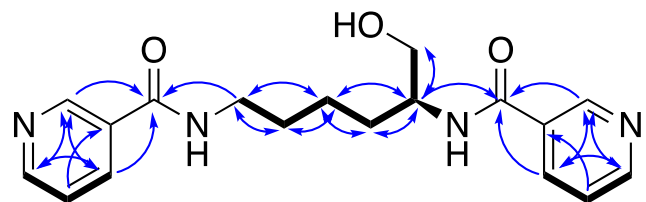

myxochelin $\mathrm{N}(\mathbf{1})$

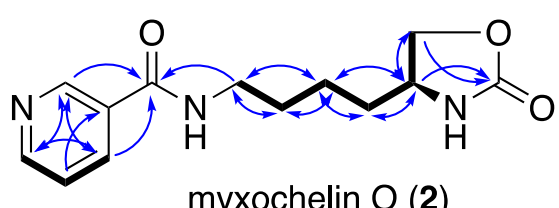

myxochelin $\mathrm{O}(2)$ 
Figure S3. Comparison of $m x c$ BGCs that have been characterized to produce myxochelin-type compounds in different myxobacterial strains. Genes were depicted in different colors according to their functions. The detailed annotation of respective gene in $m x c$ BGC of Archangium sp. SDU34 see Table S2.

Archangium sp. SDU34

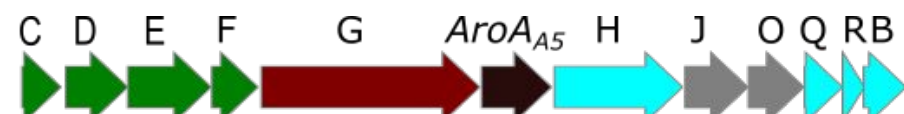

Myxococcus xanthus DK1622

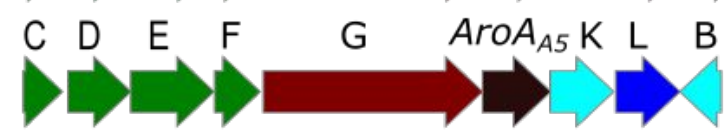

Stigmatella aurantiaca Sg a15

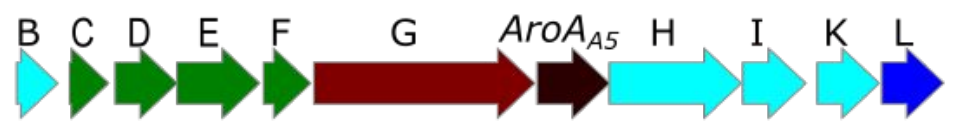

Pseudoalteromonas piscicida $\mathbf{S 2 0 4 0}$

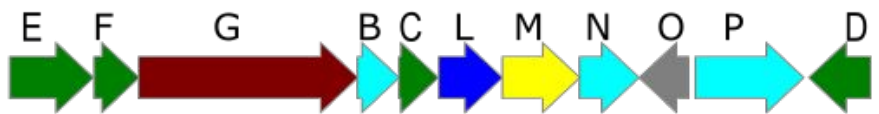

Sorangium cellulosum So ce56
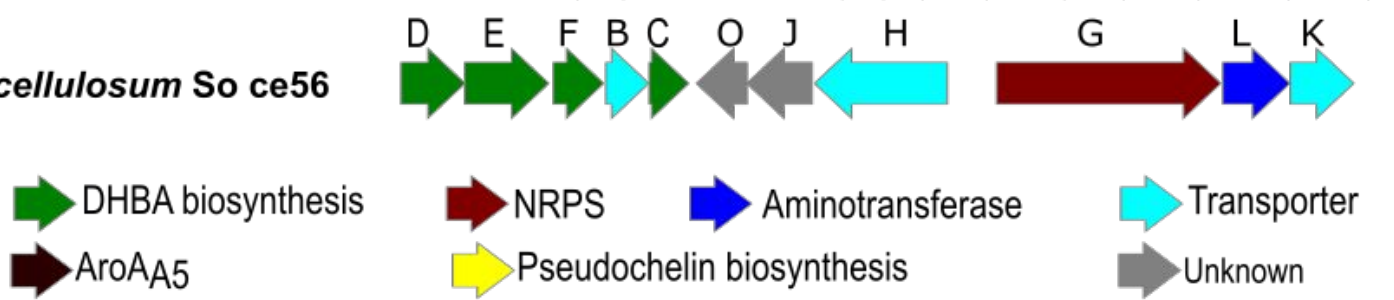
Figure S4. Recapitulation of myxochelin biosynthetic gene cluster $(m x c)$ in the sequenced myxobacteria. The total number of the sequenced strains of each myxobacterial genus, and the number of $m x c$ BGC-containing strains in each genus were labelled above the column. Remarkably, Corallococcus and Myxococcus are the mostly sequenced two genera, probably due to their relatively easier cultivability than other myxobacterial genera.

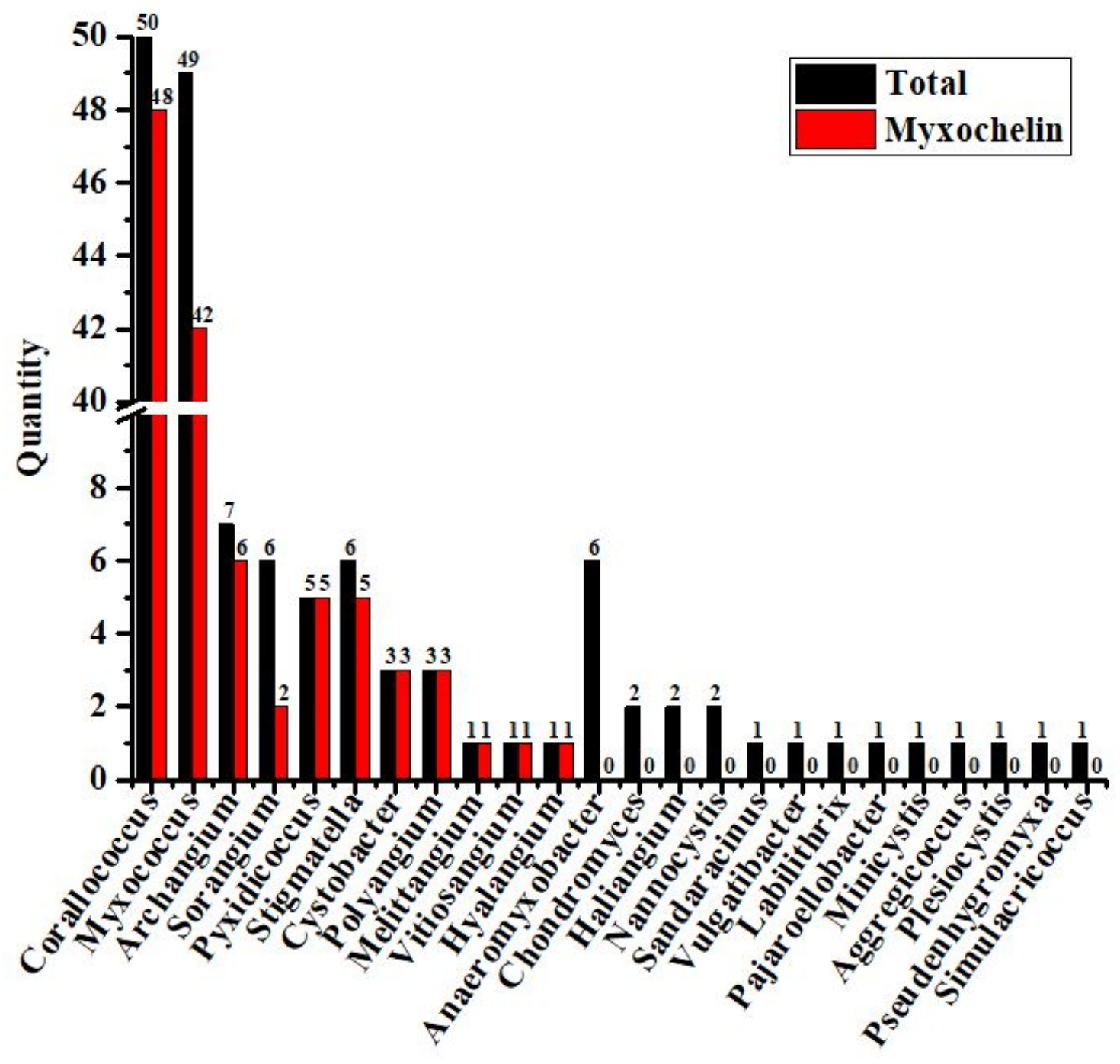


Figure S5. Phylogenetic comparison of $m x c$ BGCs from myxobacteria. The gene $m x c G$ was used as the query gene, and the $m x c$ BGC from Stigmatella aurantca $S g$ a15 was used as query cluster for CORASON ${ }^{4}$ phylogenetic reconstruction, as highlighted by red asterisk. The myxobacterial strains that have been characterized to produce myxochelins were bold highlighted, and their $m x c$ BGCs were compared in Figure S3.

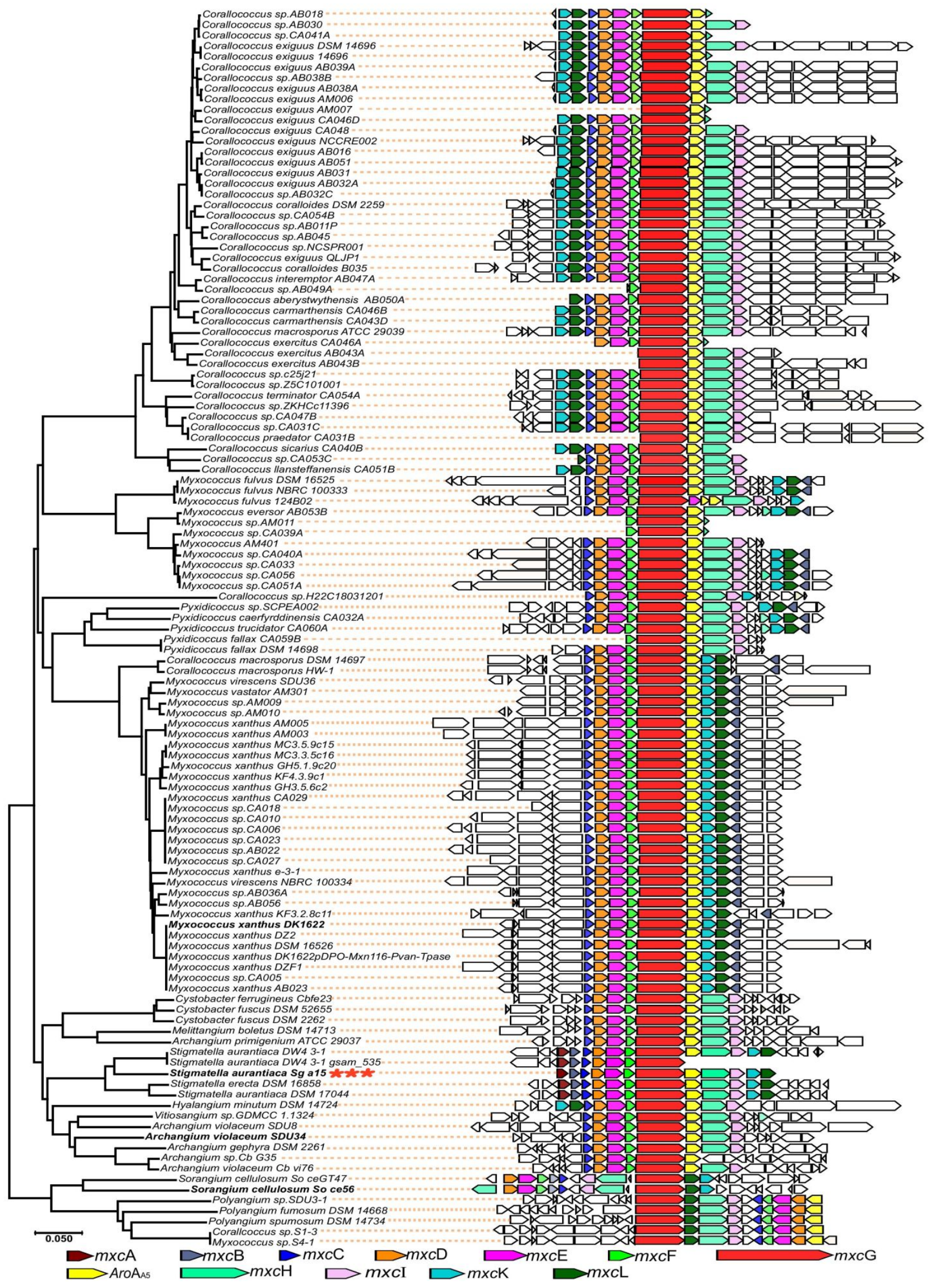


Figure S6. Comparison of MS/MS fragmentation of compounds 1-4.
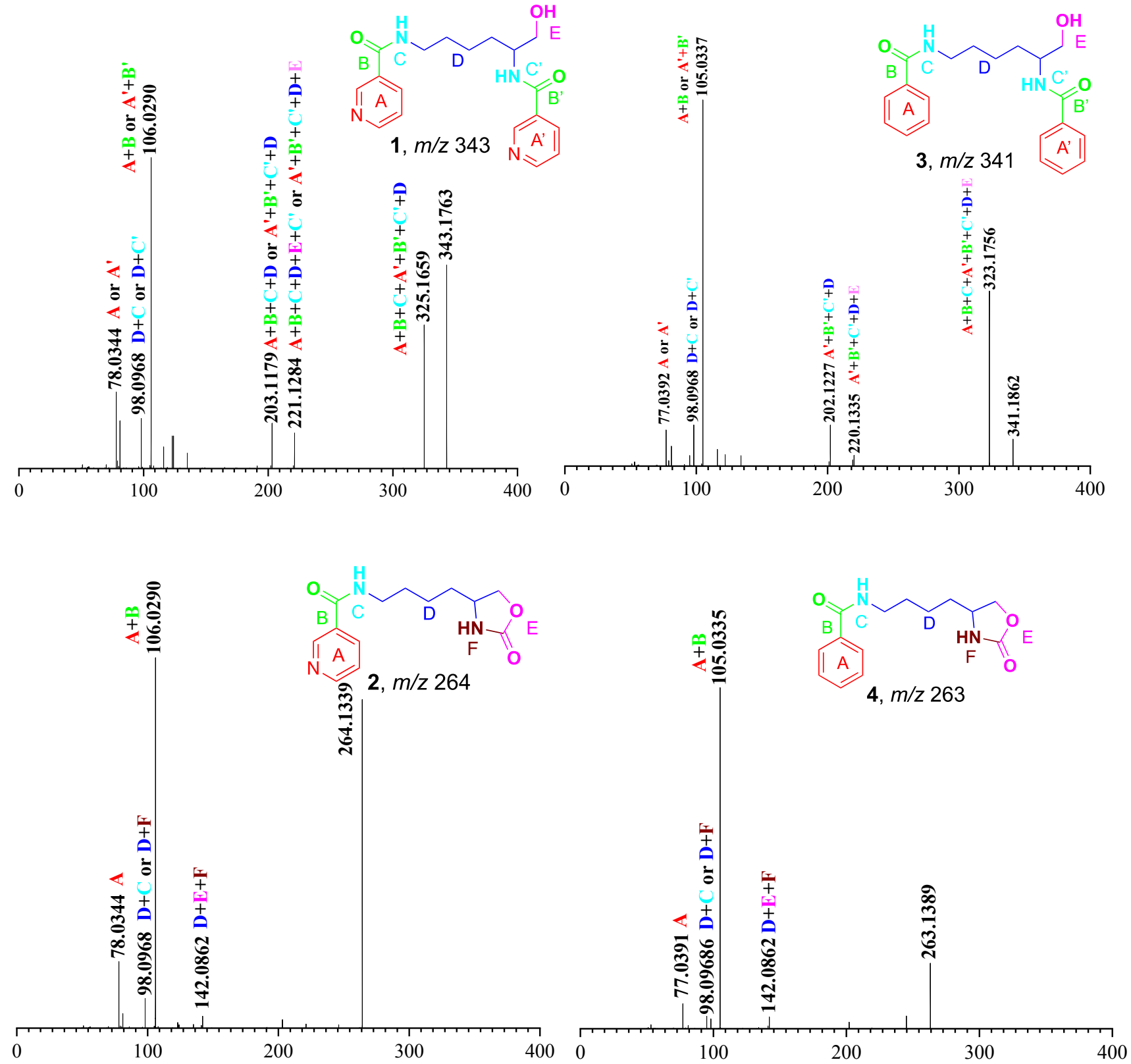
Figure S7. Phylogenetic comparison of catecholate-activating adenylation enzymes encoded in catechol-siderophore BGCs that have been functionally characterized.

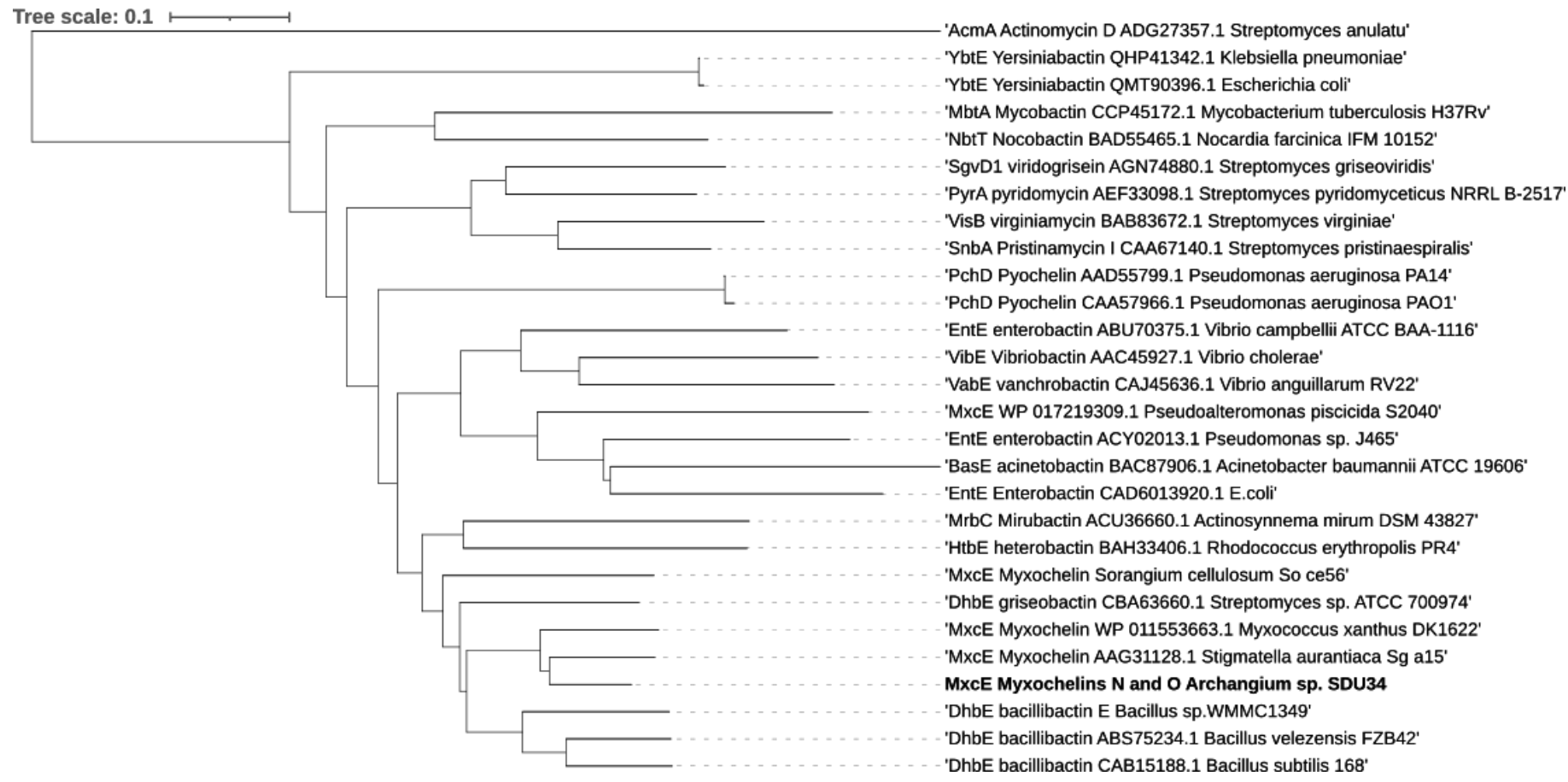


Figure S8. Sequence alignment of the catecholate-activating adenylation enzymes encoded in catechol-siderophore BGCs. The sequence for SDU34-MxcE1 was red highlighted.
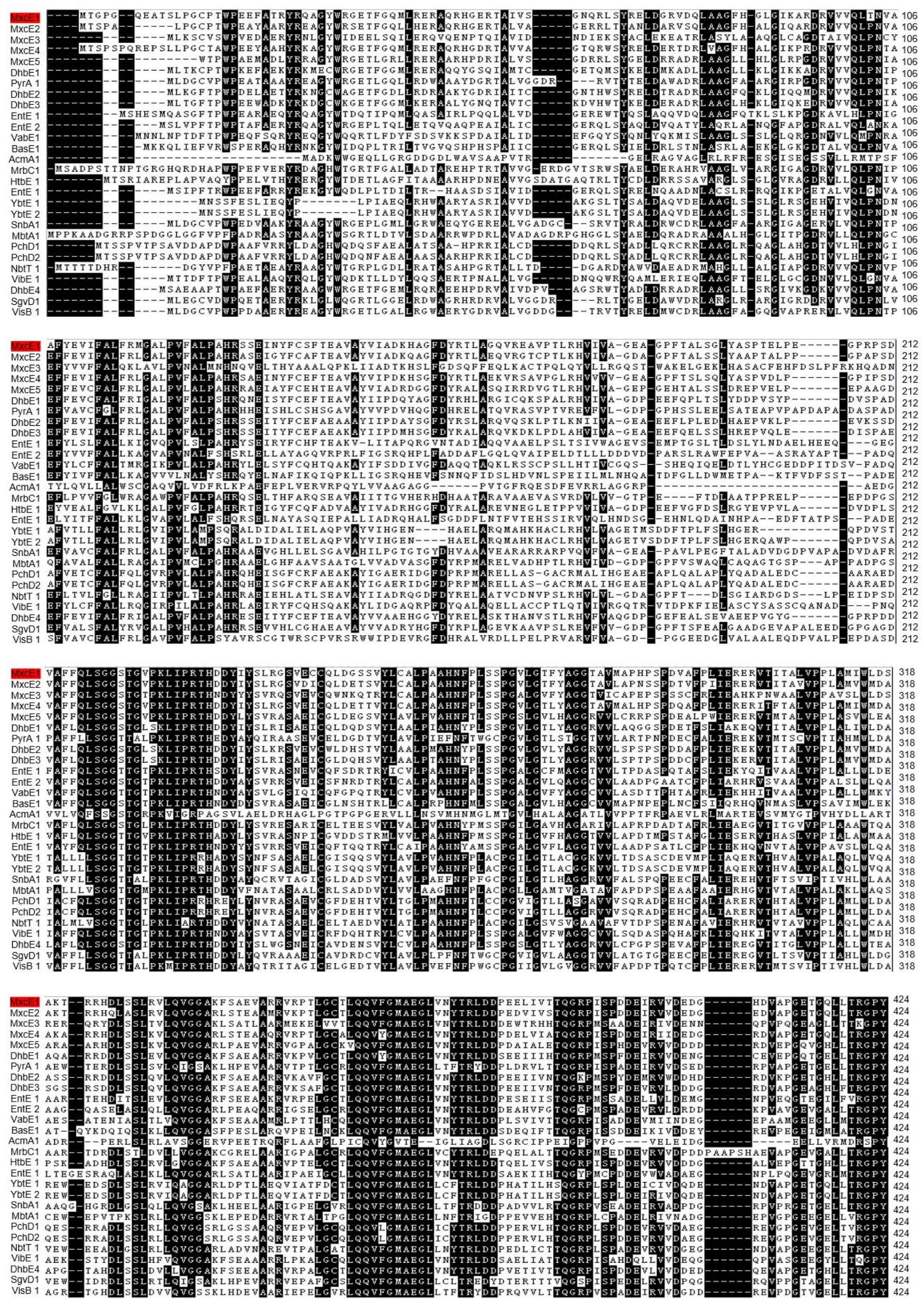

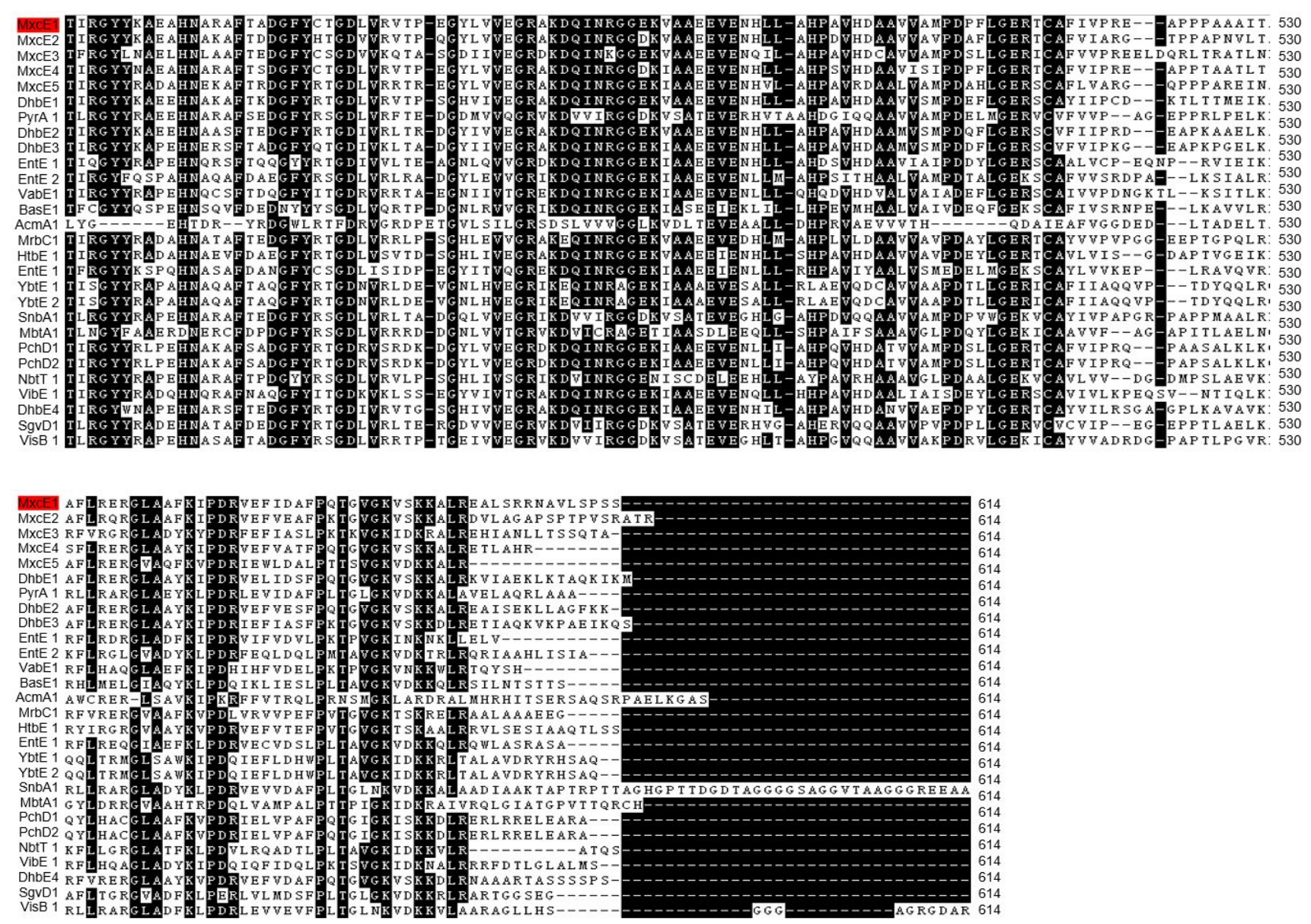
Figure S9. ${ }^{1} \mathrm{H}$ NMR $\left(600 \mathrm{MHz}, \mathrm{CD}_{3} \mathrm{OD}\right)$ spectrum of myxochelin $\mathrm{N}$ (1)

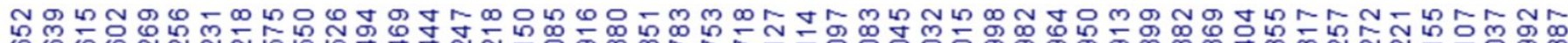
எ

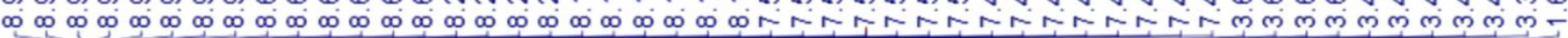<smiles>O=C(NCCCC[C@H](CO)NC(=O)c1ccccn1)c1cccnc1</smiles>

$\mathrm{H}_{2} \mathrm{O}$

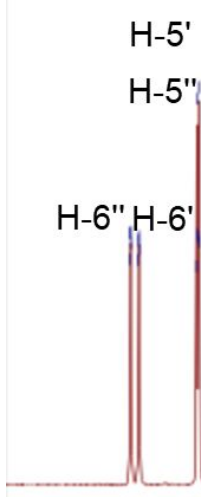

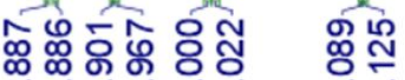

H-3" H-3'
$N(1)$

$\mathrm{H}_{2}$ 
Figure S10. ${ }^{13} \mathrm{C}$ NMR (600 MHz, $\mathrm{CD}_{3} \mathrm{OD}$ ) of myxochelin $\mathrm{N}(\mathbf{1})$
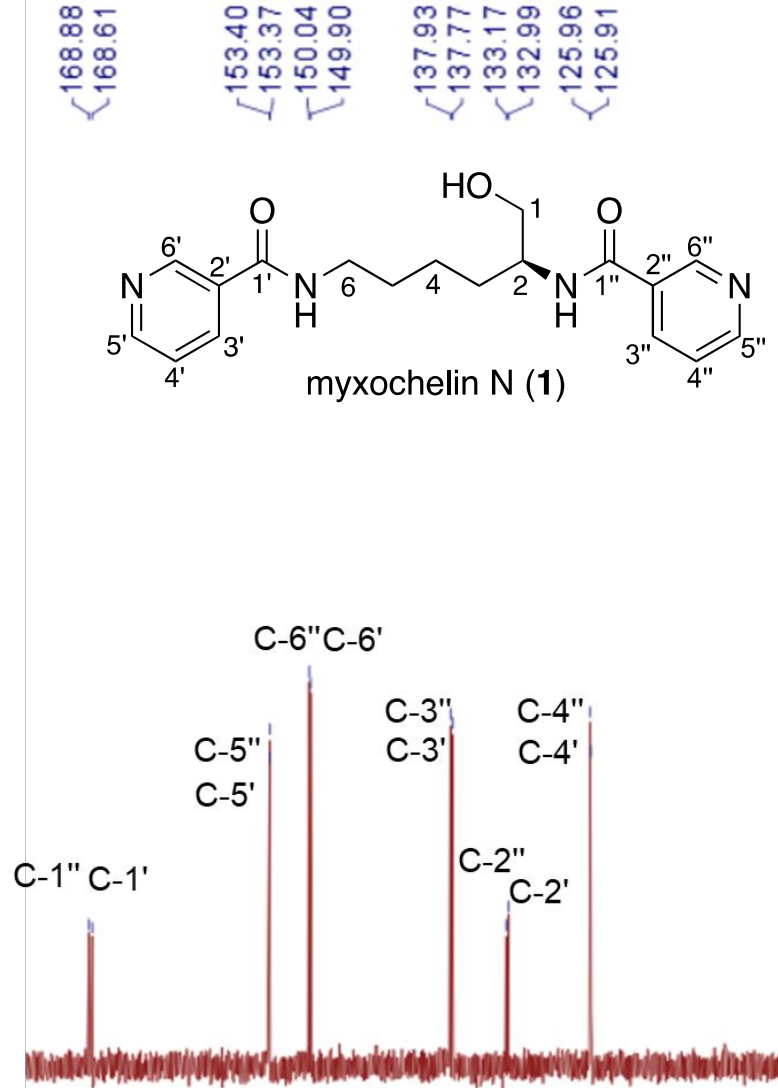

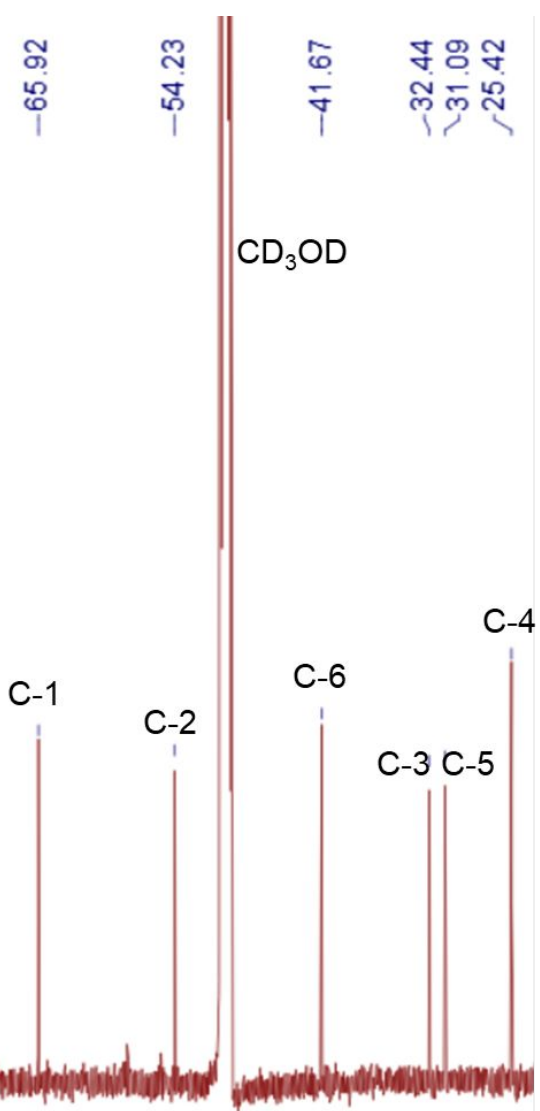

$\begin{array}{llllllllllllllllllllllllllllllll}170 & 165 & 160 & 155 & 150 & 145 & 140 & 135 & 130 & 125 & 120 & 115 & 110 & 105 & 100 & 95 & 90 & 85 & 80 & 75 & 70 & 65 & 60 & 55 & 50 & 45 & 40 & 35 & 30 & 25\end{array}$ 
Figure S11. ${ }^{1} \mathrm{H}-{ }^{13} \mathrm{C}$ HSQC NMR (600 MHz, $\left.\mathrm{CD}_{3} \mathrm{OD}\right)$ spectrum of myxochelin $\mathrm{N}$ (1)

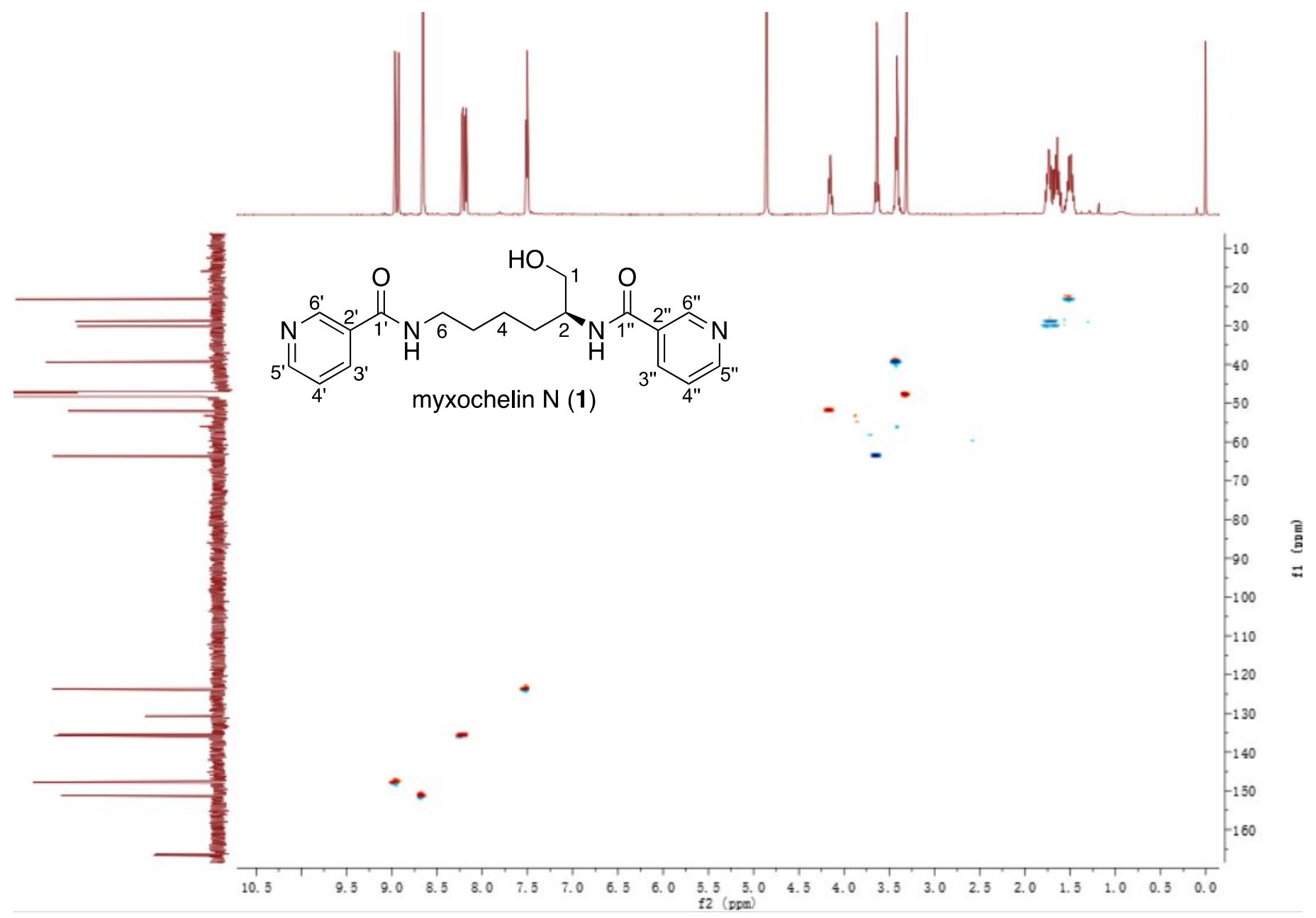


Figure S12. ${ }^{1} \mathrm{H}-{ }^{13} \mathrm{C} \mathrm{HMBC}$ NMR $\left(600 \mathrm{MHz}, \mathrm{CD}_{3} \mathrm{OD}\right)$ spectrum of myxochelin $\mathrm{N}$ (1)

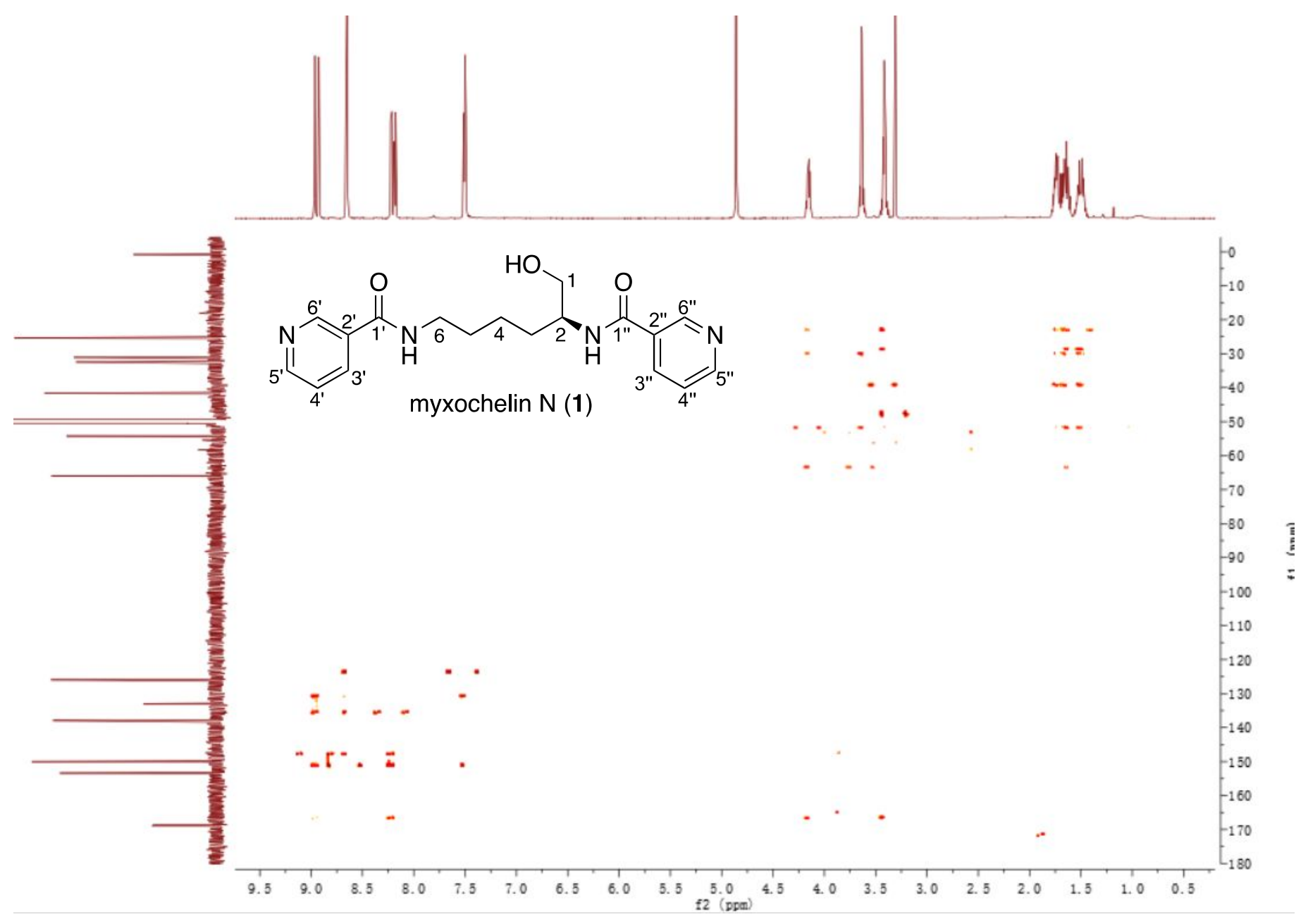


Figure S13. ${ }^{1} \mathrm{H}-{ }^{1} \mathrm{H}$ COSY NMR $\left(600 \mathrm{MHz}, \mathrm{CD}_{3} \mathrm{OD}\right)$ spectrum of myxochelin $\mathrm{N}(\mathbf{1})$

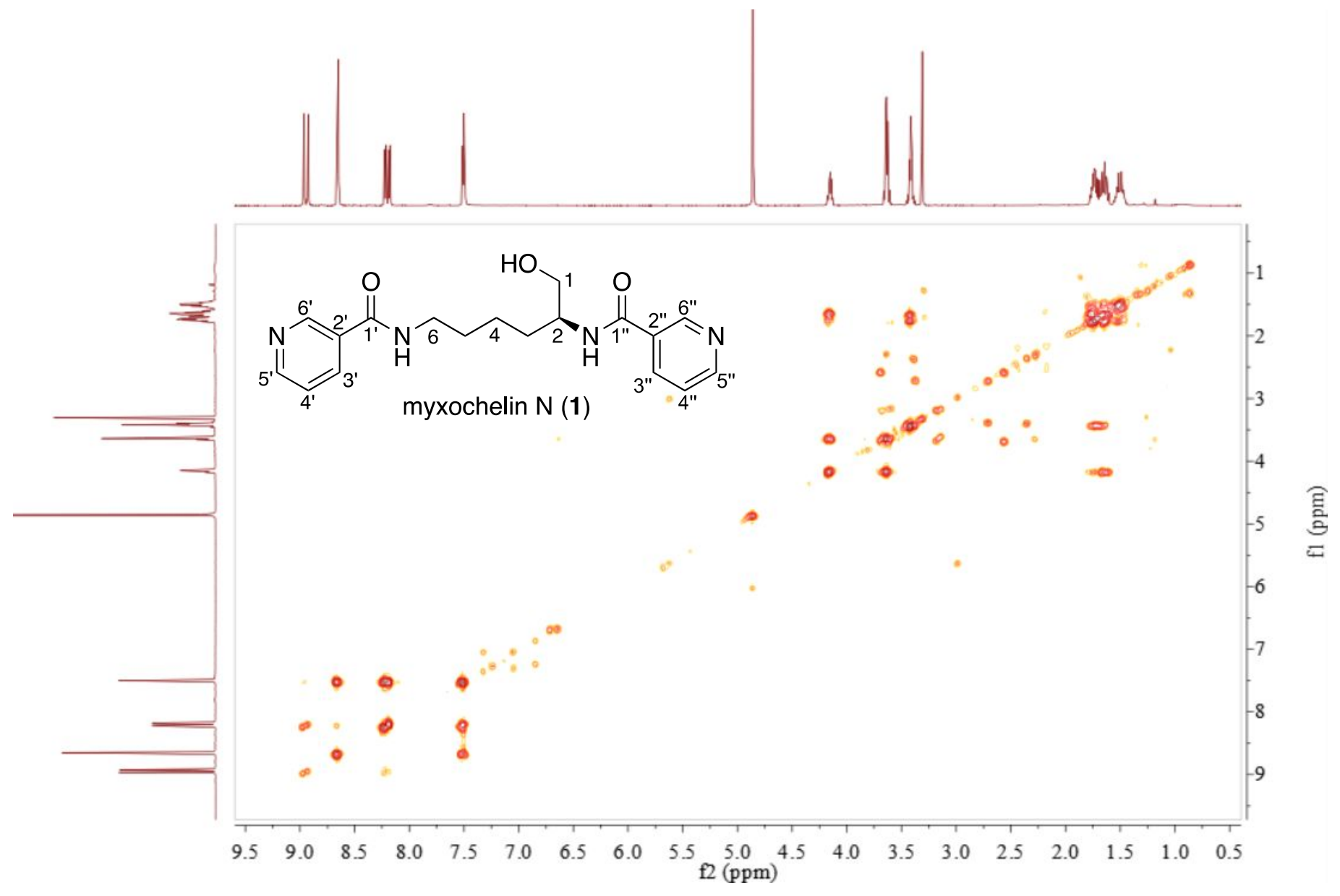


Figure S14. ${ }^{1} \mathrm{H}-{ }^{1} \mathrm{H}$ NOESY NMR $\left(600 \mathrm{MHz}, \mathrm{CD}_{3} \mathrm{OD}\right)$ spectrum of myxochelin $\mathrm{N}(1)$

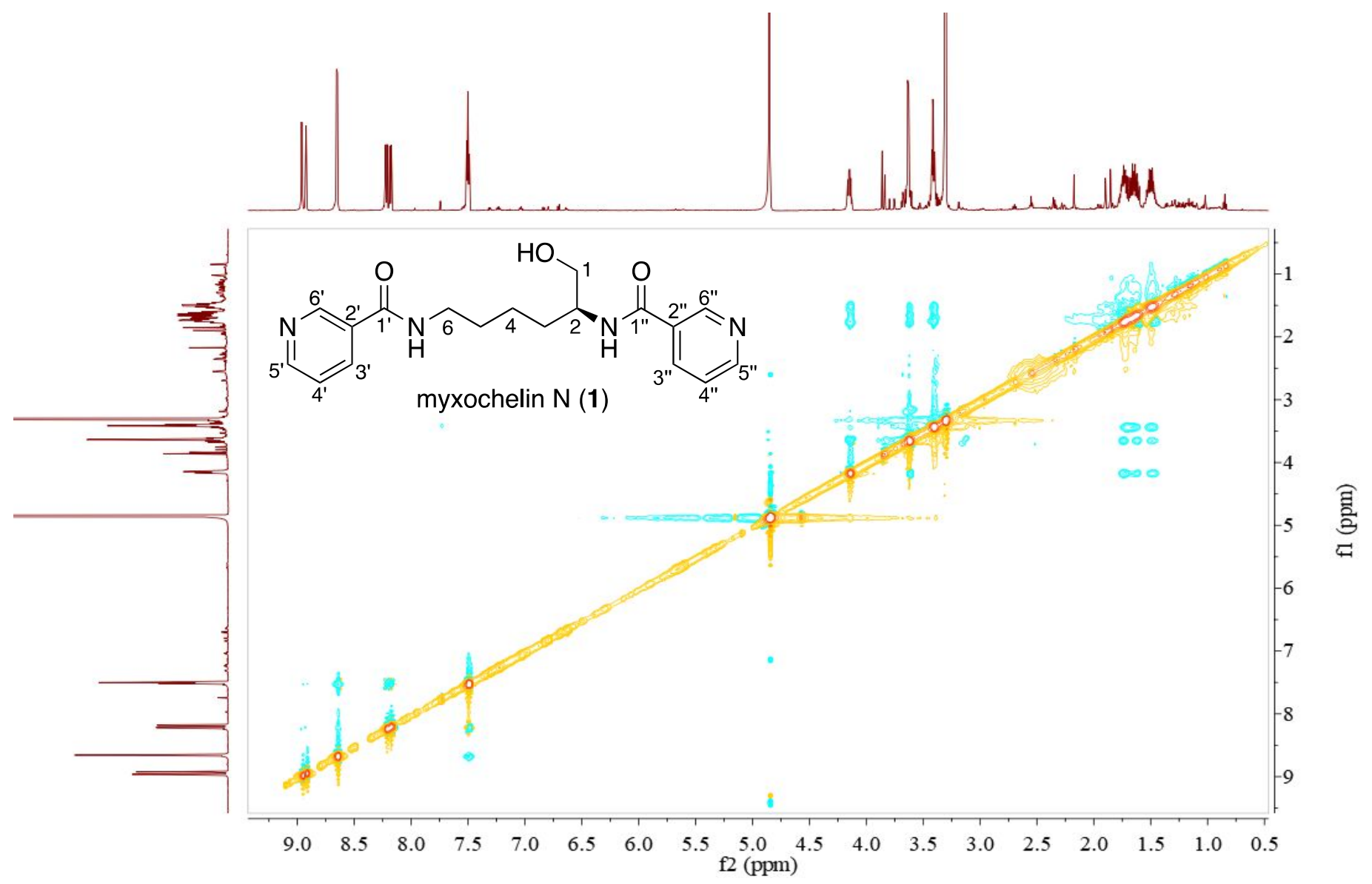

Figure S15. High-resolution mass spectrum of myxochelin N (1)

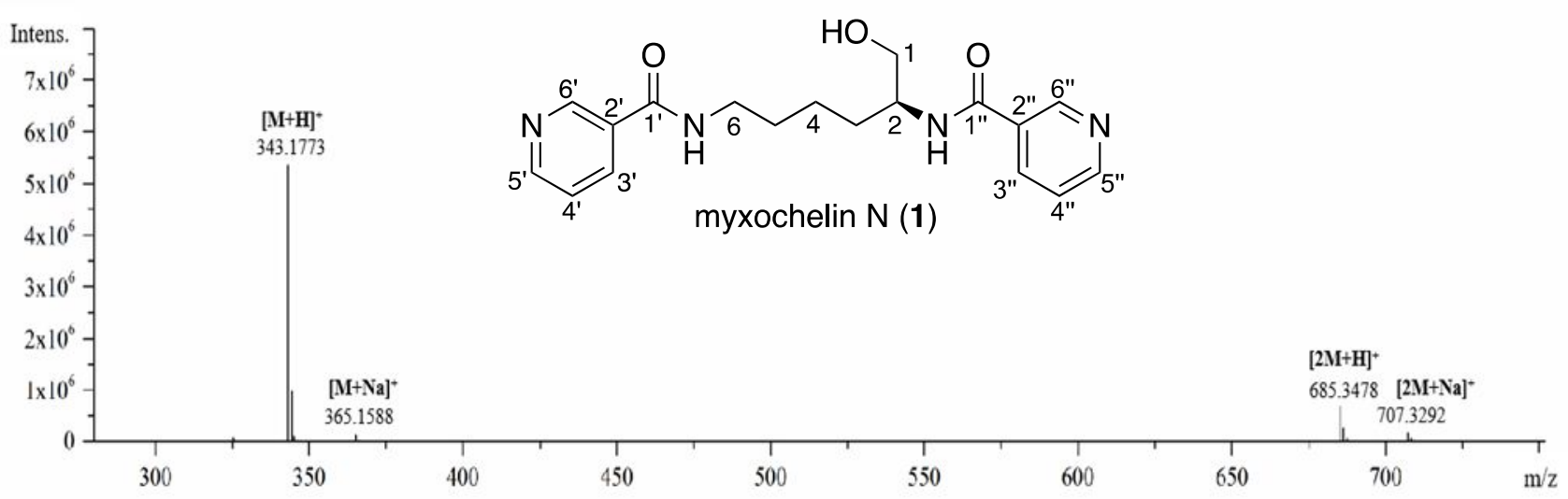


Figure S16. IR spectrum of myxochelin N (1)

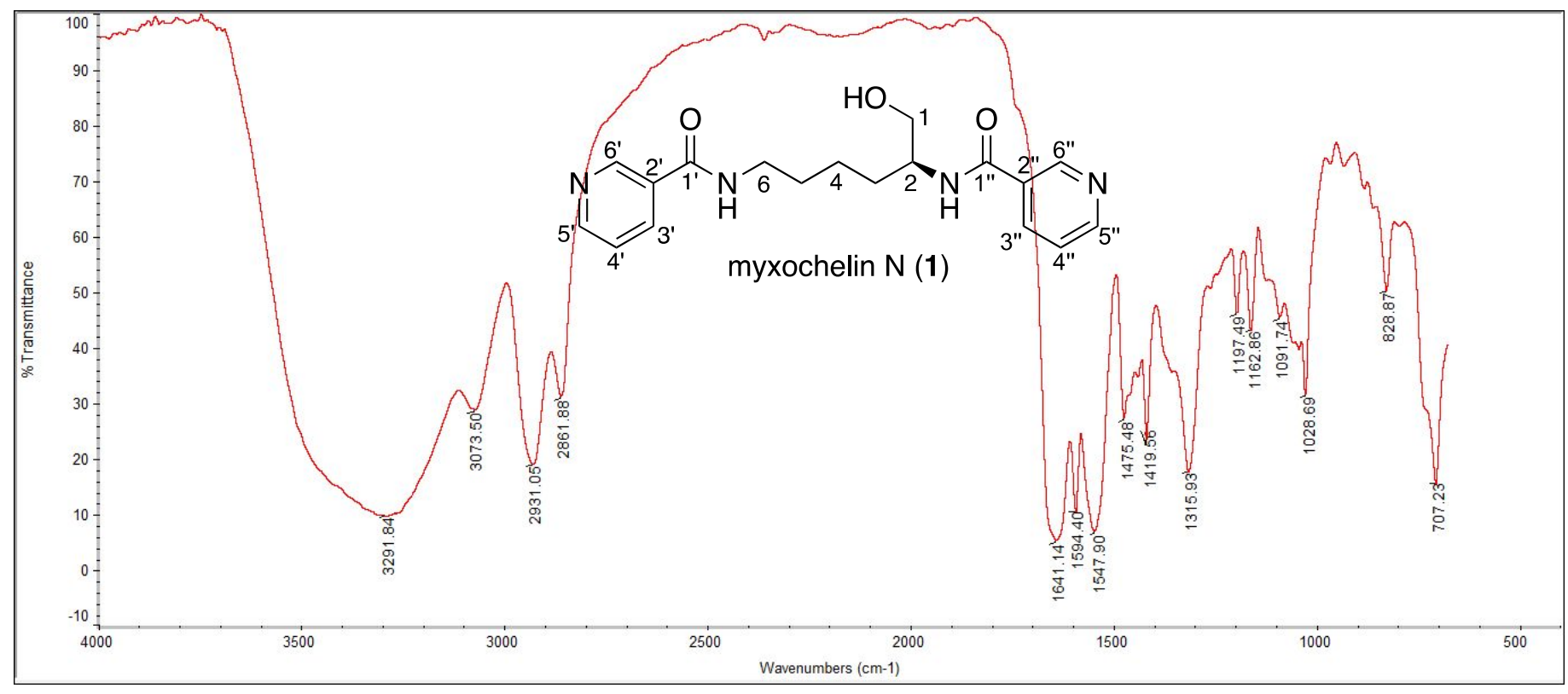

Figure S17. UV spectrum of myxochelin N (1)

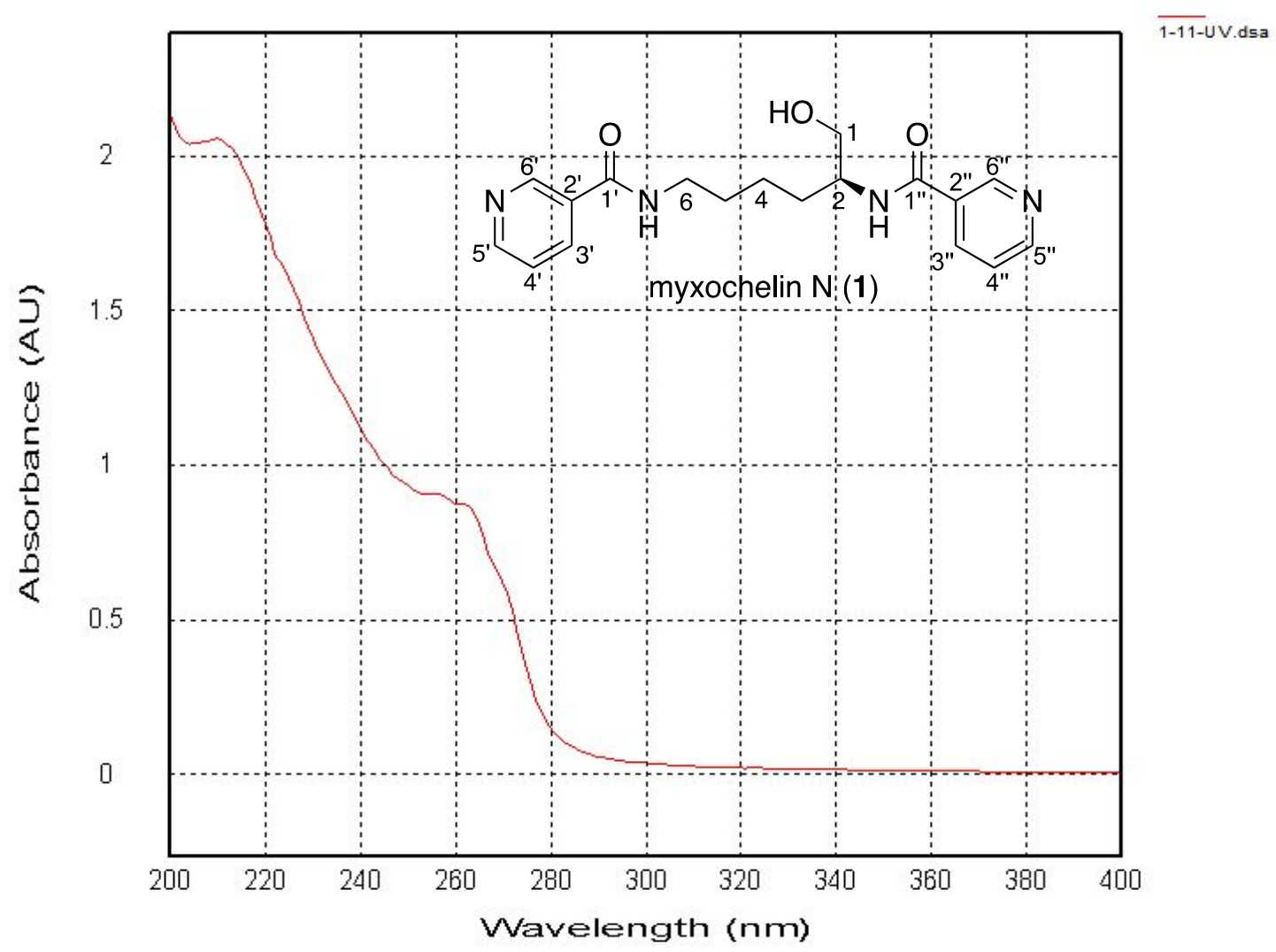


Figure S18. ${ }^{1} \mathrm{H}$ NMR (600 MHz, $\left.\mathrm{CD}_{3} \mathrm{OD}\right)$ spectrum of myxochelin $\mathrm{O}(2)$

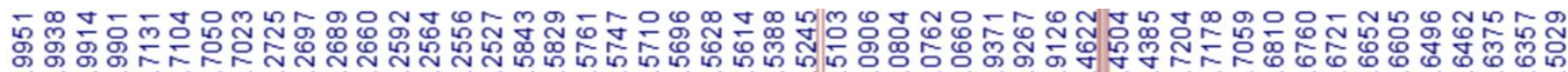

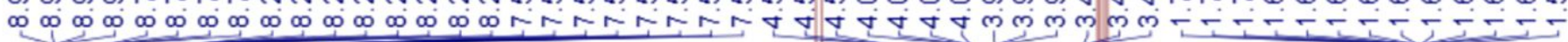<smiles>O=C1N[C@@H](CCCCNC(=O)c2cccnc2)CO1</smiles>

$\mathrm{H}_{2} \mathrm{O} \quad \mathrm{CD}_{3} \mathrm{OD}$

H-6'

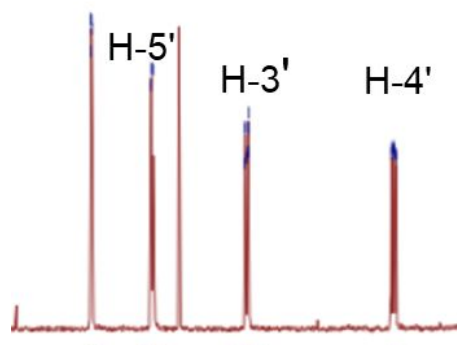

H-6

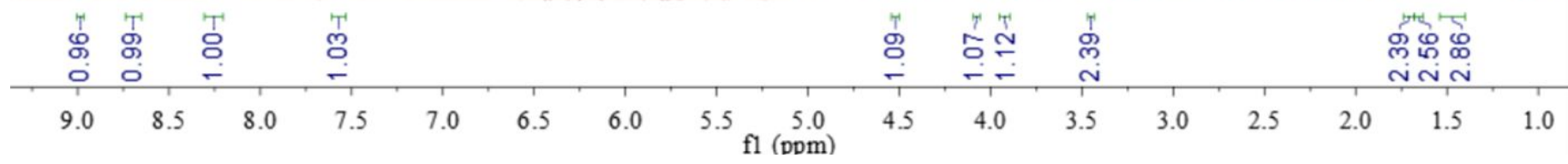


Figure S19. ${ }^{13} \mathrm{C}$ NMR (600 MHz, $\left.\mathrm{CD}_{3} \mathrm{OD}\right)$ of myxochelin $\mathrm{O}(\mathbf{2})$

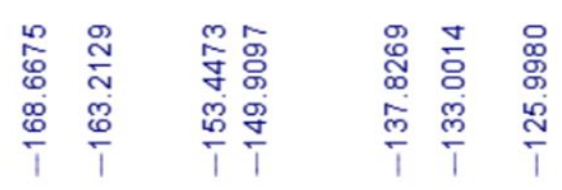

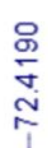

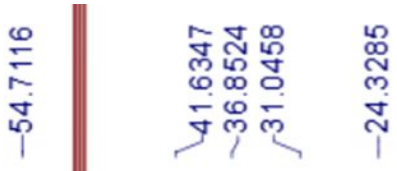<smiles>O=C(NCCCC[C@@H]1CO[C@H](C(O)O[Na])N1)c1cccnc1</smiles>

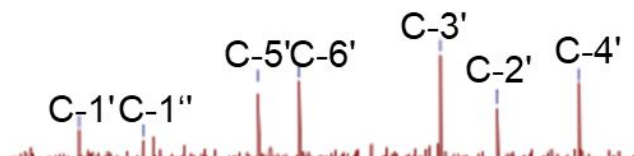

C-1

C-2 ${ }_{C-6}{ }^{C}-3^{C-5} \mathrm{C}-4$ 
Figure S20. ${ }^{1} \mathrm{H}-{ }^{13} \mathrm{C}$ HSQC NMR (600 MHz, $\left.\mathrm{CD}_{3} \mathrm{OD}\right)$ spectrum of myxochelin $\mathrm{O}(2)$

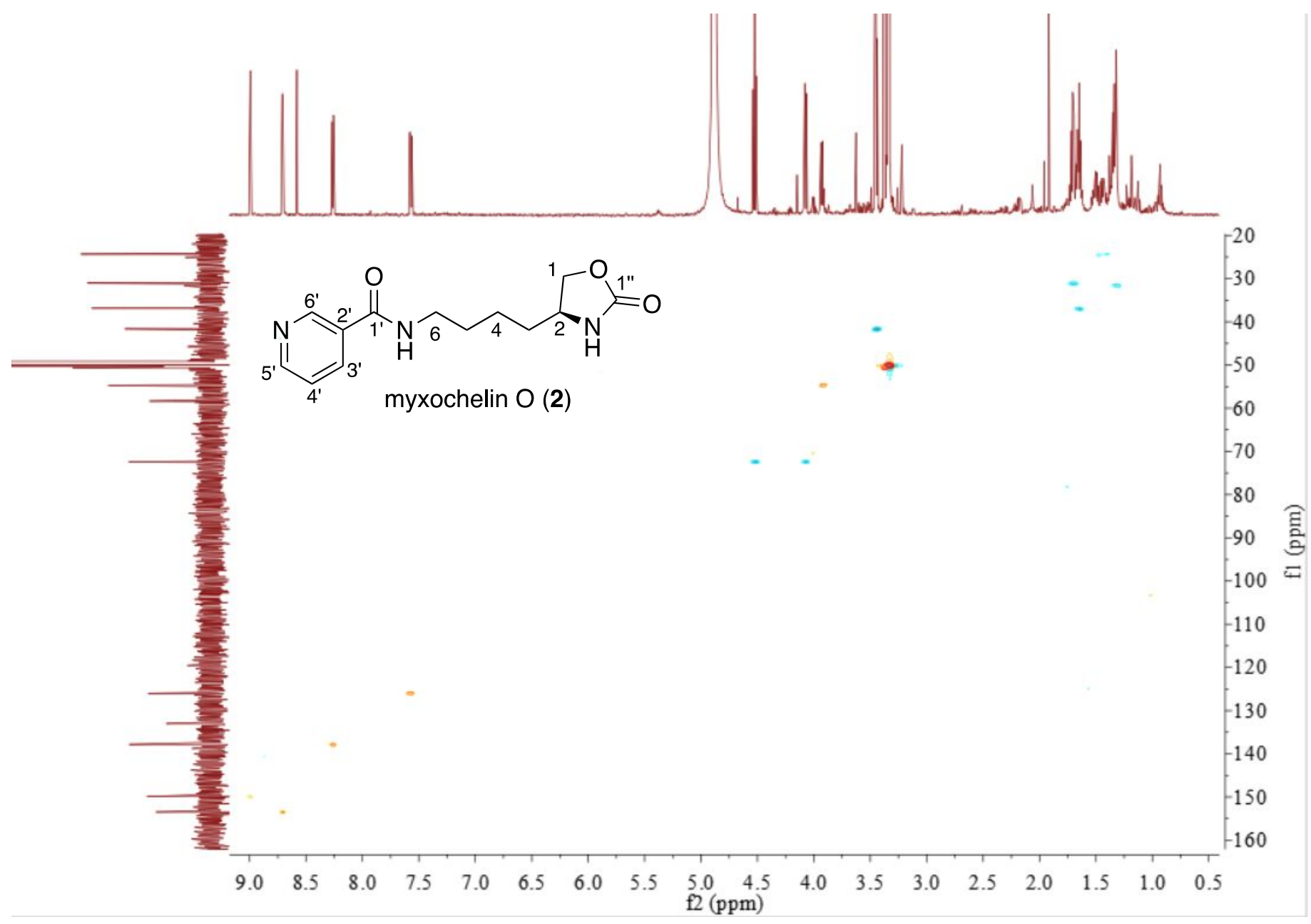


Figure S21. ${ }^{1} \mathrm{H}-{ }^{13} \mathrm{C} \mathrm{HMBC}$ NMR $\left(600 \mathrm{MHz}, \mathrm{CD}_{3} \mathrm{OD}\right)$ spectrum of myxochelin $\mathrm{O}(2)$

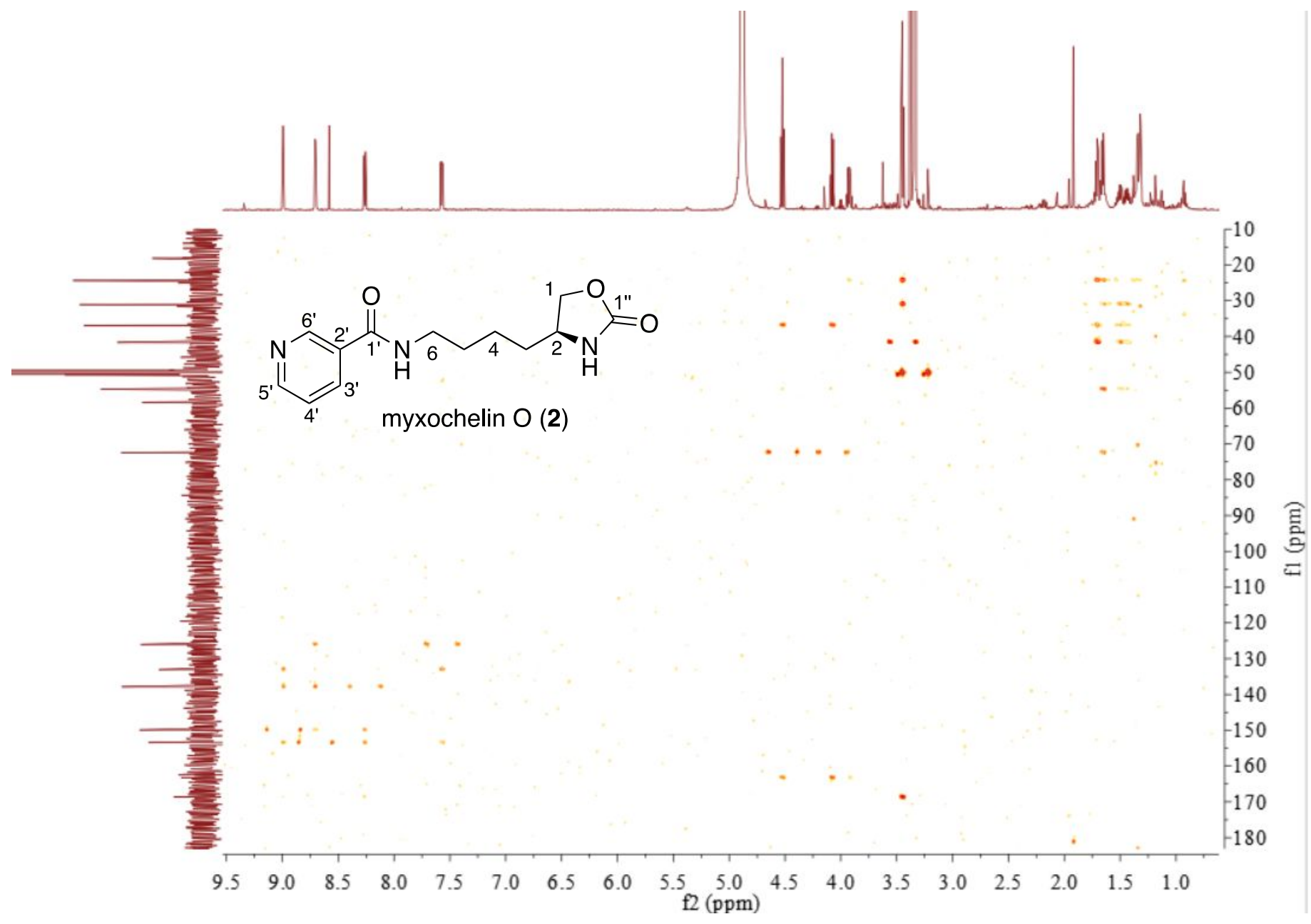


Figure S22. ${ }^{1} \mathrm{H}-{ }^{1} \mathrm{H}$ COSY NMR $\left(600 \mathrm{MHz}, \mathrm{CD}_{3} \mathrm{OD}\right)$ spectrum of myxochelin $\mathrm{O}(2)$

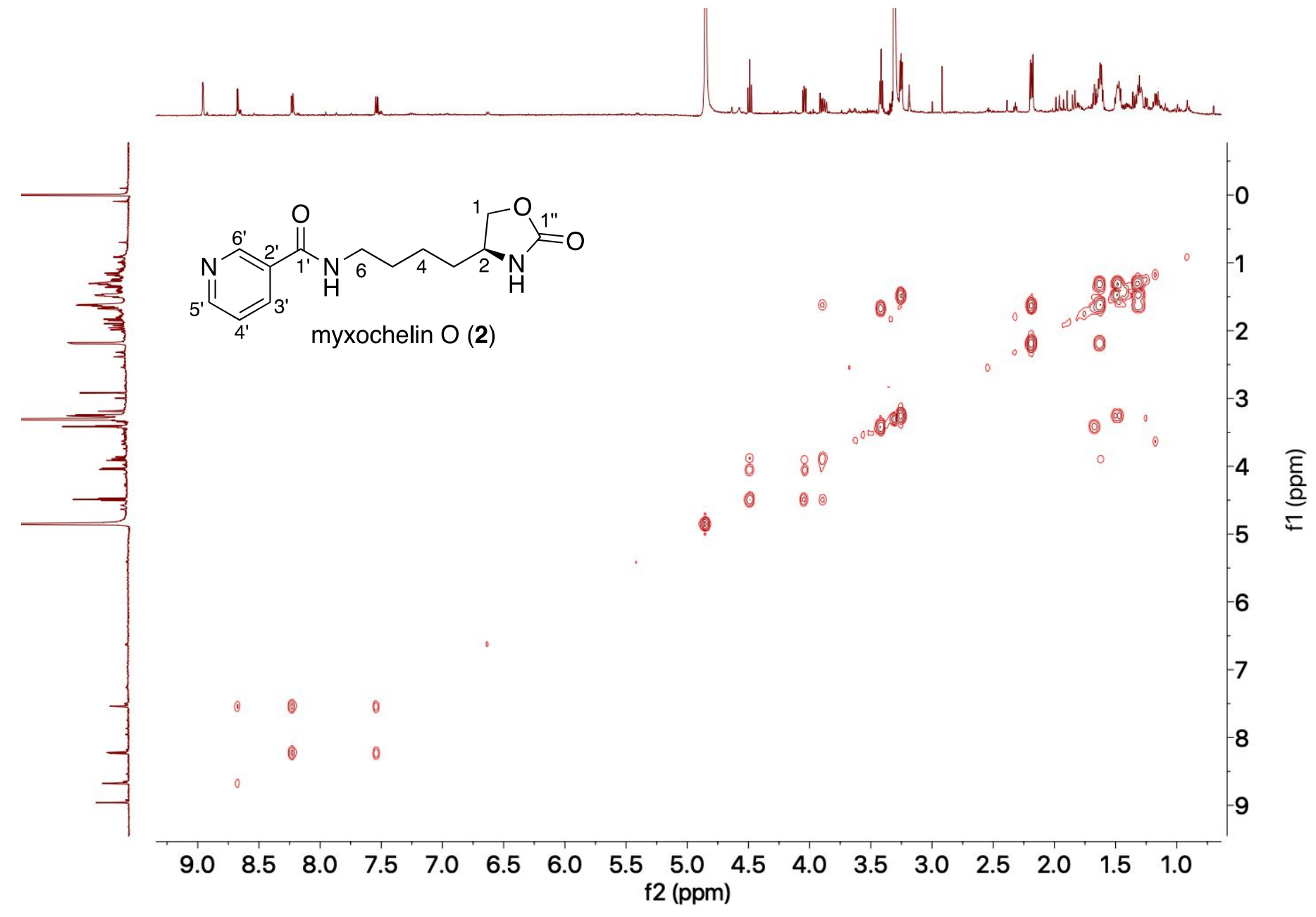


Figure S23. High-resolution mass spectrum of myxochelin O (2)

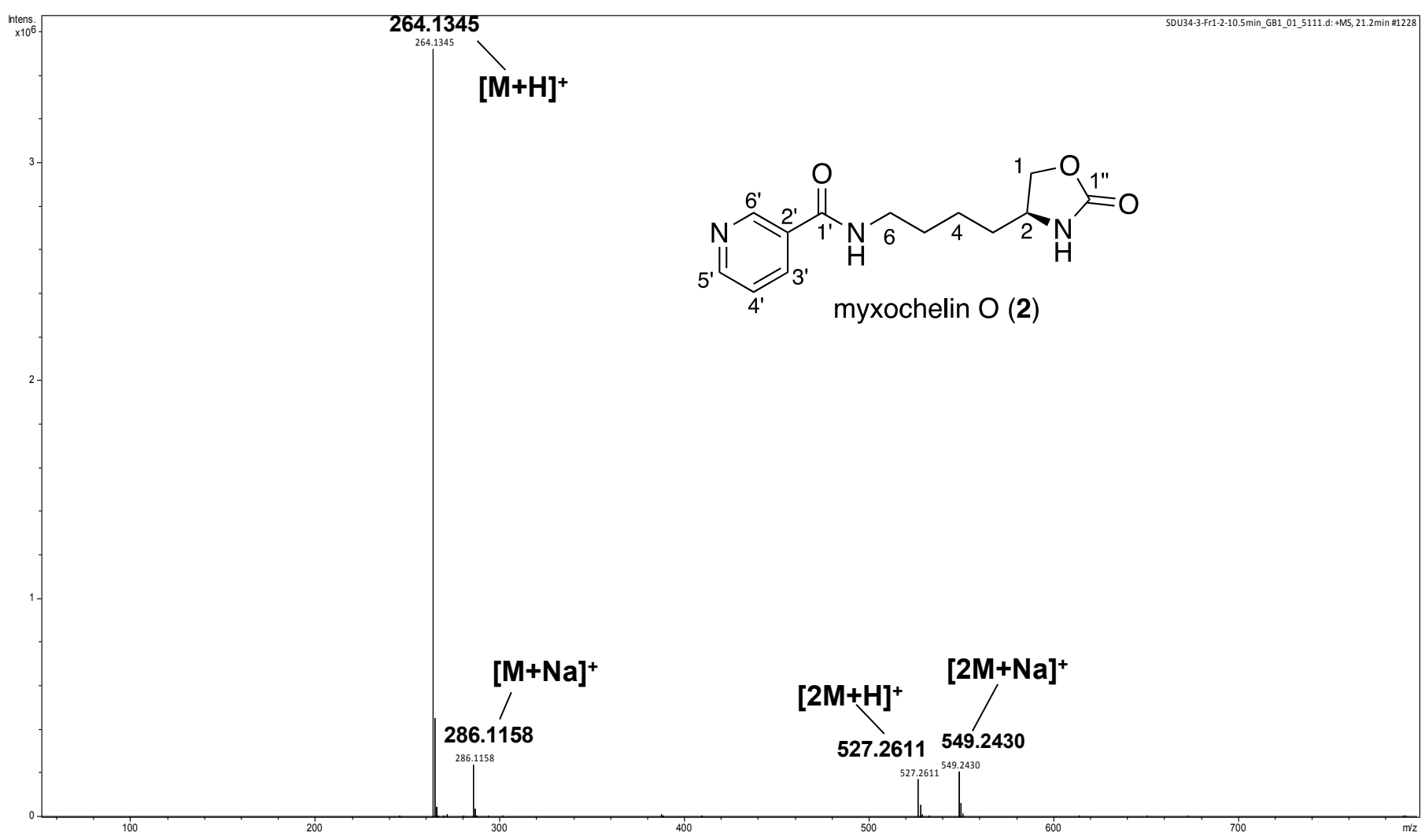


Figure S24. IR spectrum of myxochelin O (2)

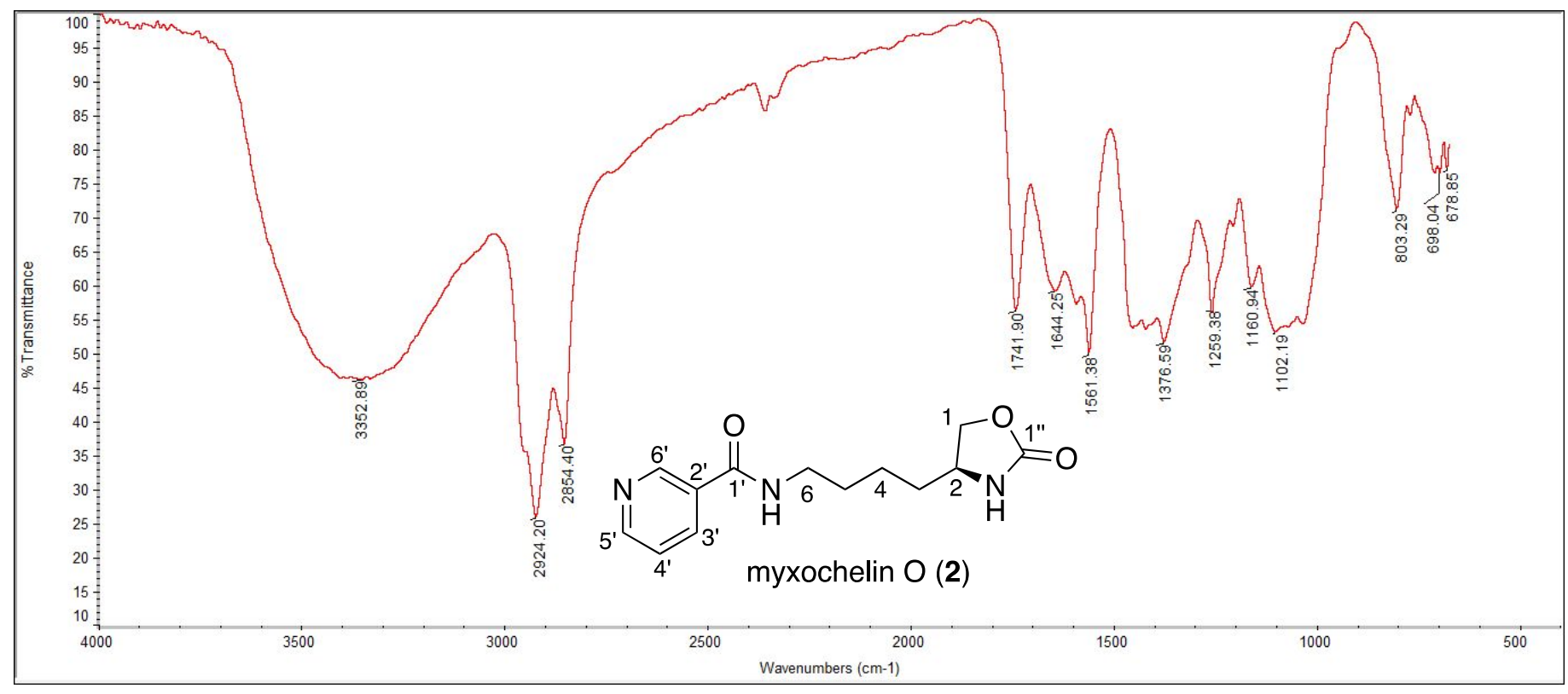

Figure S25. UV spectrum of myxochelin O (2)

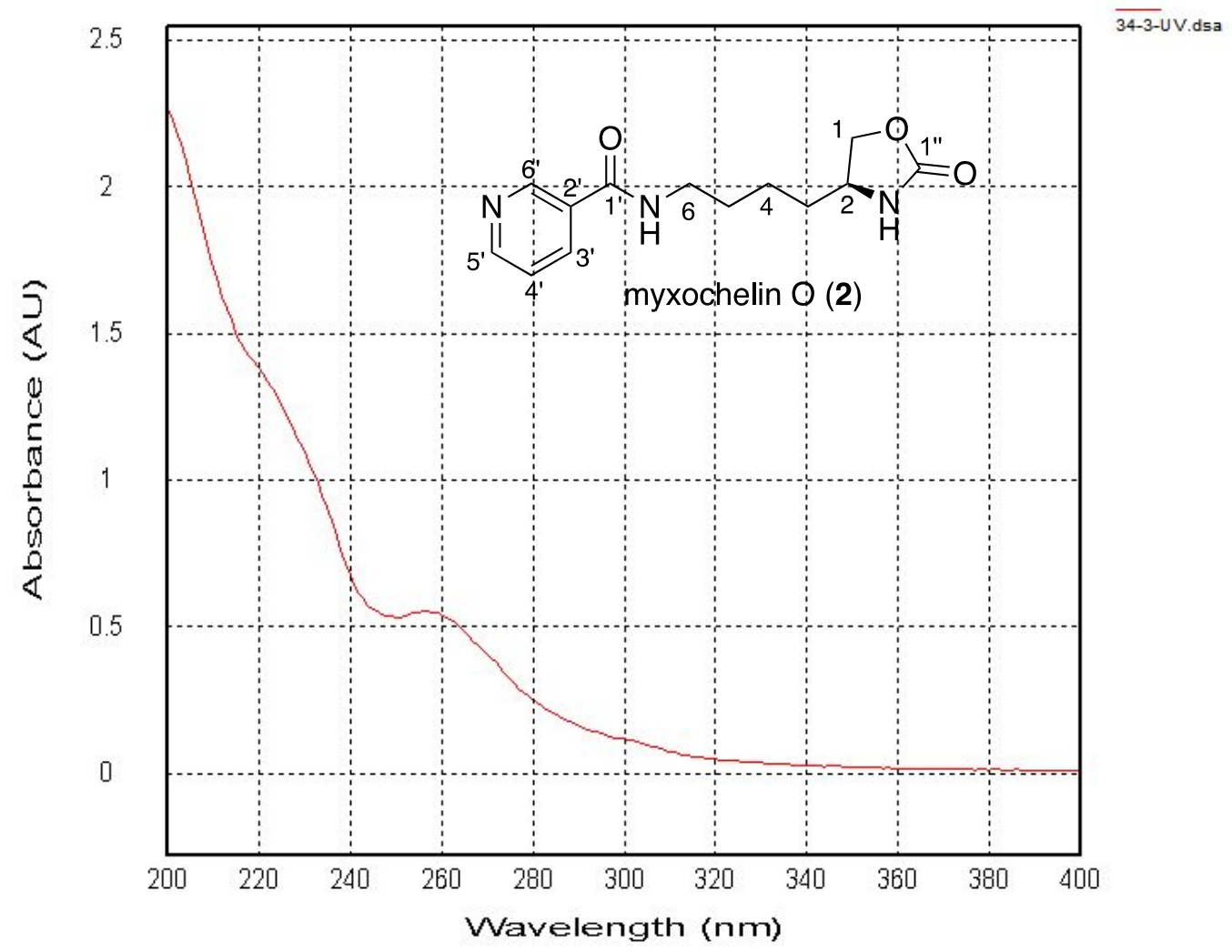




\section{References}

(1) Wu, C.; Van Wezel, G. P.; Hae Choi, Y. Identification of Novel Endophenaside Antibiotics Produced by Kitasatospora sp. MBT66. J. Antibiot. (Tokyo). 2015, 68 (7), 445-452.

(2) Zhang, F.; Barns, K.; Hoffmann, F. M.; Braun, D. R.; Andes, D. R.; Bugni, T. S. Thalassosamide, a Siderophore Discovered from the Marine-Derived Bacterium Thalassospira Profundimaris. J. Nat. Prod. 2017, 80 (9), 2551-2555.

(3) Alley, M. C.; Scudiero, D. A.; Monks, A.; Hursey, M.; Czerwinski, M. J.; Fine, D. L.; Abbott, B. J.; Mayo, J. G.; Shoemaker, R.; Boyd, M. R. Feasibility of Drug Screening with Panels of Human Tumor Cell Lines Using a Microculture Tetrazolium Assay. Cancer Res. 1988, 48 (3), 584-588.

(4) Navarro-Muñoz, J. C.; Selem-Mojica, N.; Mullowney, M. W.; Kautsar, S. A.; Tryon, J. H.; Parkinson, E. I.; De Los Santos, E. L. C.; Yeong, M.; Cruz-Morales, P.; Abubucker, S.; Roeters, A.; Lokhorst, W.; Fernandez-Guerra, A.; Cappelini, L. T. D.; Goering, A. W.; Thomson, R. J.; Metcalf, W. W.; Kelleher, N. L.; Barona-Gomez, F.; Medema, M. H. A Computational Framework to Explore Large-Scale Biosynthetic Diversity. Nat. Chem. Biol. 2020, 16 (1), 60-68. 